\title{
Use And Comparison of Topis And Electre Methods In Personnel Selection
}

\author{
Bilgin Şenel ${ }^{1}$, Mine Şenel ${ }^{1, *}$, Gizem Aydemir $^{2}$ \\ ${ }^{1}$ Department of Industrial Engineering, University of Munzur, Tunceli, Turkey \\ ${ }^{2}$ Project Manager, OBSS
}

\begin{abstract}
One of the most important function of human resources is personnel selection process. This process should be done professionally, in a short time and with minimum cost. After personnel selection process, performance of the hired person is very important for the permanence and success of the company. From this point of view, the aim of this study is to select a personnel among the candidates efficiently, with minimum cost and within a short time in one of the leading companies of Turkey in automotive sector. In order to select the right personnel all criterias which has great impact on blue collar worker selection was decided and these criterias are weighted. From the candidate pool of automotive company, appropriate candidates were selected by using TOPSIS AND ELECTRE method which are multi-criteria decision making methods
\end{abstract}

\section{Introduction}

Personnel selection is an important part of human resources management policy in any enterprise. Personnel selection process is aimed at choosing the best candidate to fill the defined vacancy in a company. It determines the input quality of personnel and thus plays an important role in human resource management [2].

Especially today, with the rapid development of the increasing globalization processes, increasing competition environment necessitates development in personnel selection processes. What makes this compulsory is that with the diversity of candidates in the human resources market, the employer wants to know which candidates qualify which candidates are best suited to perform the defined job [6].

Many businesses that understand the importance of this are now allocating a lot of funding to be one step ahead of the competition. These funds are used by many scientists to develop new decision-making techniques to make the ideal choice [10]. The objective of a selection process depends mainly on assessing the differences among candidates and predicting future performance [3]. For the solution of the complexity inherent in the selection of personnel, many scientists have tried to achieve the result using multi-criteria decision making (MCDM) in methods. [1-2-5- 6-7-10-11].

\footnotetext{
* Corresponding author: mines@anadolu.edu.tr
} 
MCDM methods deal with problems of compromise selection of the best solutions from the set of available alternatives according to objectives. Usually neither of the alternatives satisfies all the objectives therefore satisfactory decision is made instead of optimal one [1].

In this study, an evaluation was conducted on the ideal staff selection in a pioneering company operating in the automotive sector in Turkey and in accordance with the wishes of the company's senior management, TOPSIS and ELECTRE methods, which are multi criteria decision making techniques, were used to determine which method gave better results.

\section{Fundamental Properties of the Method}

\subsection{TOPSIS Method}

Using the TOPSIS method, it is necessary to compare the alternative options according to certain criteria and between the maximum and minimum values that the criteria can take against the ideal situation. A multi-criteria decision problem with $n$ alternatives and $m$ criterions can be represented by $n$ points in $m$-dimensional space. Yoon and Hwang (1980) have constructed the TOPSIS method based on the assumption that the solution alternative is the shortest distance to the ideal solution point and the farthest distance to the negative ideal solution point in some geometrical sense [9].The TOPSIS method consists of following steps [9]:

Step 1 Construct the decision matrix (A):

The decision matrix is a matrix that must be created by the decision maker. This generated matrix will be a $m x p$ dimensional matrix. Decision-making lines show decision points while columns contain factors.

$$
A_{i j}=\left[\begin{array}{cccc}
a_{11} & a_{12} & \cdot & a_{1 p} \\
a_{21} & a_{22} & \cdot & a_{2 p} \\
\cdot & \cdot & \cdot & \cdot \\
\cdot & \cdot & \cdot & \cdot \\
\cdot & \cdot & \cdot & \cdot \\
a_{m 1} & a_{m 2} & \cdot & a_{m p}
\end{array}\right]
$$

Step 2 Construct the normalized decision matrix (R):

After the decision matrix is formed, an element $r_{i j}$ of the normalized decision matrix $\mathrm{R}$ is calculated as follows;

$$
R_{i j}=\left[\begin{array}{cccc}
r_{11} & r_{12} & \cdot & r_{1 n} \\
r_{21} & r_{22} & \cdot & r_{2 n} \\
\cdot & \cdot & \cdot & \cdot \\
\cdot & \cdot & \cdot & \cdot \\
\cdot & \cdot & \cdot & \cdot \\
r_{m 1} & r & \cdot & r_{m n}
\end{array}\right]
$$

$$
r_{i j=\frac{a_{i j}}{\sqrt{\sum_{i=1}^{m} a_{i j}^{2}}}}(i=1,2, \ldots \ldots m \text { and } j=1,2, \ldots \ldots n)
$$


Step 3 Calculate the weighted normalized decision matrix $\left(\mathrm{V}_{\mathrm{ij}}\right)$ :

$$
V_{i j}=\left|\begin{array}{cccc}
w_{1} r_{11} & w_{2} r_{12} & \cdot & w_{n} r_{1 p} \\
w_{1} r_{21} & w_{2} r_{22} & \cdot & w_{n} r_{2 p} \\
\cdot & \cdot & \cdot & \cdot \\
\cdot & \cdot & \cdot & \cdot \\
\cdot & \cdot & \cdot & \cdot \\
w_{1} r_{m 1} & w_{2} r_{m 2} & \cdot & w_{n} r_{m p}
\end{array}\right| \rightarrow V_{i j}=\left|\begin{array}{cccc}
v_{11} & v_{12} & \cdot & v_{1 p} \\
v_{21} & v_{22} & \cdot & v_{2 p} \\
\cdot & \cdot & \cdot & \cdot \\
\cdot & \cdot & \cdot & \cdot \\
\cdot & \cdot & \cdot & \cdot \\
v_{m 1} & v_{m 2} & \cdot & v_{m p}
\end{array}\right|
$$

Each value of the normalized matrix is weighted with a value such as $w_{i j}$.

$$
v_{i j}=r_{i j} \cdot w_{i j}
$$

The weighted normalized value $v_{i j}$ is calculated in the left way;

Where $w_{j}$ is the weight of the $\mathrm{j}$-th criterion, $\sum_{j=1}^{n} w_{j}=1$

Step 4 Determine Ideal $\left(\mathrm{A}^{+}\right)$and Negative ideal $\left(\mathrm{A}^{-}\right)$solutions :

Once the weighted normalized matrix ( $\underline{\mathrm{V}}_{\mathrm{ij}}$ matrix$)$ is obtained, the maximal values of each column are determined, provided that our goal is maximization, provided that it depends on the structure of the problem. These maximum values are our ideal solution values. Then, minimum values for each column are obtained again. This is the negative ideal solution value. If our goal is minimization, the values obtained will be the exact opposite. The notation for obtaining ideal and negative ideal solution values is shown below.

$\left\{\begin{array}{c}\max \\ i\end{array}\right.$ on condition that $\} \rightarrow A^{+}=\left\{v_{1}^{+}, v_{2}^{+}, \ldots \ldots \ldots v_{n}^{+}\right\}$max values for each column

$\left\{\begin{array}{c}\text { min } \\ i\end{array}\right.$ on condition that $\} \rightarrow A^{-}=\left\{v_{1}^{-}, v_{2}^{-}, \ldots \ldots \ldots v_{n}^{-}\right\}$min values for each column

Step 5 Calculate the separation measures from the positive and the negative ideal solution :

The n-dimensional Euclidean distance method is applied to measure the separation distances of each alternative from the ideal solution and negative-ideal solution. In order to be able to calculate the distance of the ideal and negative ideal point, following formulas are used :

$$
S_{i}^{+}=\sqrt{\sum_{j=1}^{N}\left(V_{i j}-V_{j}^{+}\right)^{2}}
$$

$\underline{\text { Negative Ideal Distance }}$

$$
S_{i}^{-}=\sqrt{\sum_{j=1}^{N}\left(V_{i j}-V_{j}^{-}\right)^{2}}
$$

Step 6 Calculate the relative closeness to the positive ideal solution :

Ideal and negative ideal solution is used to calculate the ideal resolving relative closeness of each decision point. The ideal solution is symbolized by the relative closeness $C_{i}^{+}$. Where $C_{i}^{+}$value takes a value in the range $0 \leq C_{i}^{+} \leq 1$ and while $C_{i}^{+}=1$ represents the absolute solution closeness to the ideal solution of the corresponding decision point, $C_{i}^{-}$represents the absolute solution closeness to the negative ideal solution of the corresponding decision point.

$$
C_{i}^{+}=\frac{S_{i}^{-}}{S_{\bar{i}}^{-}+S_{\bar{i}}^{-}}
$$

Step 7 Rank the preference order or select the alternative closest to 1:

A set of alternatives now can be ranked by descending order of value of $C_{i}^{+}$. 


\subsection{ELECTRE Method}

ELECTRE (Elemination and Choice Expressing Reality) method is a multi-decision method first proposed by Benayoun and Roy in 1966. The method is based on binary superiority comparisons between alternative decision points for each rating factor [4]. In the ELECTRE Method concordance and discordance indexes are defined as measurements of satisfaction and dissatisfaction for decision maker in choosing one alternative over anothor. These indexes are then used to analyze the outranking relations among the alternatives [8]. The method is solved by the following steps [9]. The first three steps (Preparation of the decision matrix, the normalized decision matrix and weighted matrix) are not included here because they are the same as TOPSIS method.

Step 4 Ascertainment of Concordance $\mathrm{C}_{\mathrm{kl}}$ to Discordance $\mathrm{D}_{\mathrm{kl}}$ set :

In determining the concordance set, y matrix is used. The decision points for the evaluation factor are compared with another one and the sets are determined using the relationship shown in the following formula;

$$
C_{k l}=\left\{J, y_{k j} \geq y_{l j}\right\} \quad \mathrm{j}=1,2,3, \ldots \ldots \mathrm{n}
$$

The formula is basically based on comparing the sizes of the line elements relative to each other. Each concordance set $\left(C_{k l}\right)$ corresponds to an discordance set $\left(D_{k l}\right)$. The elements of the discordance set consist of $\mathrm{J}$ values that do not belong to the concordance set. On complimentation of $\left(C_{k l}\right)$, we obtain the discordance interval set $\left(D_{k l}\right)$ using;

$$
D_{k l}=\left\{J, y_{k j}<y_{l j}\right\}=J-C_{k l} \quad \mathrm{j}=1,2,3, \ldots . . \mathrm{n}
$$

Step 5 Calculation of The Concordance (C) and Discordance (D) Matrices

The relative value of the elements in the concordance matrix $\mathrm{C}$ is calculated by means of the concordance index. The concordance index $\mathrm{C}_{\mathrm{kl}}$ is the sum of the weights associated with the criteria contained in the concordance set. That is;

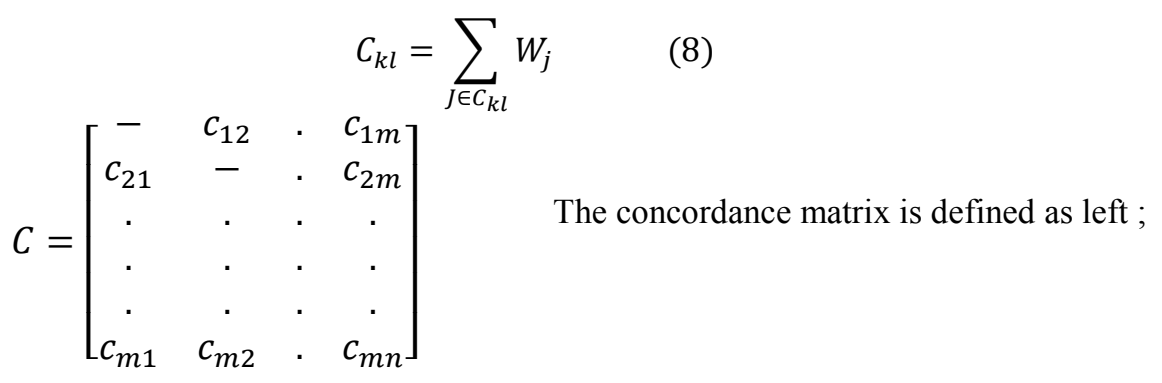

The discordance matrix $\mathrm{D}_{\mathrm{kl}}$ elements is defined by formula.

$$
D_{k l}=\frac{\max _{j \in D_{k l}}\left|y_{k j}-y_{l j}\right|}{\max _{j}\left|y_{k j}-y_{l j}\right|}
$$




$$
D=\left[\begin{array}{cccc}
- & d_{12} & \cdot & d_{1 m} \\
d_{21} & - & \cdot & d_{2 m} \\
\cdot & \cdot & \cdot & \cdot \\
\cdot & \cdot & \cdot & \cdot \\
\cdot & \cdot & \cdot & \cdot \\
d_{m 1} & d_{m 2} & \cdot & d_{m n}
\end{array}\right]
$$

Then, using discordance index set, we can obtain discordance matrix as left;

Step 6 Determine The Concordance (F) and Discordance Dominance (G) Matrix :

For finding matrix (F), it is needed to compute threshold value $(\bar{c})$ as follow:

$$
\begin{gathered}
\bar{c}=\frac{1}{m(m-1)} \sum_{k=1}^{m} c_{k l} \quad \text { ( } m \text { is dimension of matrix) } \\
\left\{\begin{array}{lll}
f_{k l}=1, & \text { if } c_{k l} \geq \bar{c} & \text { The left inequaliti } \\
f_{k l}=0 & \text { if } \quad c_{k l}<\bar{c} & \text { element of matrix }
\end{array}\right.
\end{gathered}
$$

The left inequalities mean that if each element of matrix $C_{k l}$, is greater than or equal to $\bar{c}$, than 1 would be set in matrix $(F)$. (corresponding element)

To determine discordance dominance matrix, we calculate matrix of $(G)$.

$$
\begin{aligned}
\bar{d}= & \frac{1}{m(m-1)} \sum_{k=1}^{m} \sum_{l}^{m} d_{k l} \\
& \left\{\begin{array}{cll}
g_{k l}=1 & \text { if } & d_{k l} \geq \bar{d} \\
g_{k l}=0 & \text { if } & d_{k l}<\bar{d}
\end{array}\right.
\end{aligned}
$$$$
\text { ( } \bar{d} \text { : Discordance Threshold Value) }
$$

The elements of the matrix $(G)$. take the value 0 or 1 . There is no value on the diagonal of the matrix $(G)$ as it shows the same decision points.

Step 7 Determine the aggregate dominance matrix $(E)$ :

Matrix $\mathrm{E}$ is performed by multiplying corresponding elements of $\mathrm{F}$ and $\mathrm{G}$.

$$
\mathrm{e}_{k l}=f_{k l} \cdot g_{k l}
$$

The matrix $(E)$ is dimensioned according to the matrix $(F)$ and $(G)$ and consists of the values 0 and 1 .

Step 8 Eliminate the less favourable alternative and rank them:

We must scan the line of matrix $(E)$, line that has the highest score should be chosen as the best one.

\section{Application}

Since the first 3 steps of the TOPSIS and ELECTRE Methods to be used in practice are the same (a decision matrix, a normalized decision matrix and a weighted normalized 
decision matrix) 3 steps for both methods were created in the same way. Afterwards, the analysis were carried out according to the steps of both methods.

\subsection{TOPSIS}

At this step, the first question is which criteria are important for recruitment. As a result of interviews with business managers, it has been determined that the following criteria are taken into account in recruitment. Then, a total of 65 applications were made and each candidate was asked to answer the previously determined criteria. A matrix was prepared based on the answers received.

In determining the weight of the factors, business managers, team leaders, and recruitment staff were asked which criteria weighted the recruitment process. The points awarded are distributed in such a way that the sum of the criterion values is 1 point. The weights of the criteria are shown in table 1.

Table 1. Criteria and Weights

\begin{tabular}{|c|c|c|c|}
\hline CRITERIA & WEIGHTS & CRITERIA & WEIGHTS \\
\hline C1. Education Status & 0,099535124 & $\begin{array}{l}\text { C20. Task } \\
\text { Responsibility }\end{array}$ & 0,019917012 \\
\hline C2. Graduated Section & 0,086828512 & C21. Mobility & 0,02127499 \\
\hline C3. Birthyear & 0,01300578 & C22. Anger & 0,019917012 \\
\hline C4. Gender & 0,011823437 & $\begin{array}{l}\text { C23. Uncontrolled } \\
\text { Behavior }\end{array}$ & 0,022632968 \\
\hline C5. Marital status & 0,010641093 & C24. Self-discipline & 0,023990946 \\
\hline C6. Number of children & 0,007094062 & C25. Sociability & 0,017201056 \\
\hline C7. Homeland & 0,007882291 & $\begin{array}{l}\text { C26. Strength } \\
\text { Resistance }\end{array}$ & 0,022180309 \\
\hline C8. Smoking & 0,016158696 & C27. Harmony & 0,023538287 \\
\hline C9. Driver's license & 0,013399895 & $\begin{array}{l}\text { C28. Attention and } \\
\text { Concentration }\end{array}$ & 0,040685543 \\
\hline $\begin{array}{l}\text { C10. Heavy and Dangerous } \\
\text { Work Certificate }\end{array}$ & 0,012217551 & $\begin{array}{l}\text { C29. Visual } \\
\text { Comparison }\end{array}$ & 0,037555886 \\
\hline C11. the work is registered & 0,012217551 & $\begin{array}{l}\text { C30. Follow Visual } \\
\text { Instruction }\end{array}$ & 0,0383383 \\
\hline C12. Criminal record & 0,016946926 & $\begin{array}{l}\text { C31. Mechanical- } \\
\text { Technical Tendency }\end{array}$ & 0,035991058 \\
\hline $\begin{array}{l}\text { C13. Military Status for Male } \\
\text { Candidates }\end{array}$ & 0,014976353 & $\begin{array}{l}\text { C32. Verbal } \\
\text { Instructions following }\end{array}$ & 0,0383383 \\
\hline C14. Computer Skill & 0,033849129 & C33. General Image & 0,026194145 \\
\hline $\begin{array}{l}\text { C15. Course / Certificate } \\
\text { Information }\end{array}$ & 0,029819471 & $\begin{array}{l}\text { C34. General Attitude } \\
\text { and Behavior }\end{array}$ & 0,03077812 \\
\hline $\begin{array}{l}\text { C16. Foreign Language } \\
\text { Information }\end{array}$ & 0,020148291 & 35. Willingness & 0,032087827 \\
\hline $\begin{array}{l}\text { C17. Work Experience Period } \\
\text { (years) }\end{array}$ & 0,029819471 & $\begin{array}{l}\text { C36. Listening and } \\
\text { Understanding }\end{array}$ & 0,033397535 \\
\hline C18. Experience Clarity & 0,02127499 & C37. Reliability & 0,032087827 \\
\hline C19. Layout & 0,023538287 & & \\
\hline
\end{tabular}


After the decision matrix formed by the data taken in the direction of the criterion has been put forward, Eq.(1) has been used to form the normalized decision (A) matrix. Then, the weighted normalized decision matrix was formed by Eq.(2). After the weighted normalized decision matrix is constructed, two solution sets have been established by using the Eq.(3) for the positive ideal solution and Eq.(4) for the negative ideal solution. In the next step, the deviations of the evaluation factor values for each decision point from the positive ideal and negative ideal solution sets were found. while the Eq.(5) formula is used to find positive ideal deviations, the Eq.(6) formula is used to find negative ideal deviations.

Positive ideal relative closeness values $\left(S_{i}^{+}\right)$and negative ideal relative closeness values $\left(S_{i}^{-}\right)$were obtained in the direction of the obtained results. By using the obtained differences in Eq.(7), the relative closeness to the ideal solution of each decision point was found and the results are given in Table 2 .

Table 2. Relative closeness to the positive ideal solution

\begin{tabular}{|l|l|l|l|l|l|l|l|l|l|}
\hline $\mathbf{1}$ & 0,537037 & $\mathbf{1 4}$ & 0,408097 & $\mathbf{2 7}$ & 0,462341 & $\mathbf{4 0}$ & 0,454777 & $\mathbf{5 3}$ & 0,451602 \\
\hline $\mathbf{2}$ & 0,509735 & $\mathbf{1 5}$ & 0,555171 & $\mathbf{2 8}$ & 0,477382 & $\mathbf{4 1}$ & 0,463658 & $\mathbf{5 4}$ & 0,305041 \\
\hline $\mathbf{3}$ & 0,478116 & $\mathbf{1 6}$ & 0,082199 & $\mathbf{2 9}$ & 0,600987 & $\mathbf{4 2}$ & 0,526335 & $\mathbf{5 5}$ & 0,390352 \\
\hline $\mathbf{4}$ & 0,553469 & $\mathbf{1 7}$ & 0,488091 & $\mathbf{3 0}$ & 0,454299 & $\mathbf{4 3}$ & 0,476687 & $\mathbf{5 6}$ & 0,354146 \\
\hline $\mathbf{5}$ & 0,441776 & $\mathbf{1 8}$ & 0,519921 & $\mathbf{3 1}$ & 0,355324 & $\mathbf{4 4}$ & 0,494757 & $\mathbf{5 7}$ & 0,292422 \\
\hline $\mathbf{6}$ & 0,402958 & $\mathbf{1 9}$ & 0,45544 & $\mathbf{3 2}$ & 0,445327 & $\mathbf{4 5}$ & 0,497137 & $\mathbf{5 8}$ & 0,542106 \\
\hline $\mathbf{7}$ & 0,429644 & $\mathbf{2 0}$ & 0,465373 & $\mathbf{3 3}$ & 0,459771 & $\mathbf{4 6}$ & 0,428475 & $\mathbf{5 9}$ & 0,464441 \\
\hline $\mathbf{8}$ & 0,495668 & $\mathbf{2 1}$ & 0,448104 & $\mathbf{3 4}$ & 0,458169 & $\mathbf{4 7}$ & 0,517146 & $\mathbf{6 0}$ & 0,498541 \\
\hline $\mathbf{9}$ & 0,5489 & $\mathbf{2 2}$ & 0,528596 & $\mathbf{3 5}$ & 0,375747 & $\mathbf{4 8}$ & 0,548075 & $\mathbf{6 1}$ & 0,477263 \\
\hline $\mathbf{1 0}$ & 0,433854 & $\mathbf{2 3}$ & 0,395076 & $\mathbf{3 6}$ & 0,097782 & $\mathbf{4 9}$ & 0,532101 & $\mathbf{6 2}$ & 0,528715 \\
\hline $\mathbf{1 1}$ & 0,444864 & $\mathbf{2 4}$ & 0,492628 & $\mathbf{3 7}$ & 0,483895 & $\mathbf{5 0}$ & 0,45384 & $\mathbf{6 3}$ & 0,538521 \\
\hline $\mathbf{1 2}$ & 0,524402 & $\mathbf{2 5}$ & 0,518692 & $\mathbf{3 8}$ & 0,557004 & $\mathbf{5 1}$ & 0,382064 & $\mathbf{6 4}$ & 0,323209 \\
\hline $\mathbf{1 3}$ & 0,484628 & $\mathbf{2 6}$ & 0,381532 & $\mathbf{3 9}$ & 0,423482 & $\mathbf{5 2}$ & 0,216875 & $\mathbf{6 5}$ & 0,460184 \\
\hline
\end{tabular}

As a result of Table 2, the most suitable candidates for the business were determined to be the ranking result from small value to the large value. Candidates with the highest score were candidates for 29,38, 15 and 4 respectively, while 16th candidate is the lowest scored candidate.

\subsection{ELECTRE}

In this method, as in the TOPSIS method, 65 candidates were examined. We tried to make the best choice by using the Electre method in the direction of the data received from these candidates. While the first 3 steps of this method are performed as done in TOPSIS, the other steps will require different operations. Therefore, firstly, Concordance $\left(C_{k l}\right)$ and Discordance $\left(D_{k l}\right)$ sets were found by using the decision matrix, normalized decision matrix and weighted decision matrices obtained in the TOPSIS method.

Candidates for the same criteria as the values obtained from the weighted normalized matrix are compared with each other and the row number of the greatest value is determined as Concordance and the row number of the smallest name is determined as Discordance. 
After this step, matrices of Concordance and Discordance were established. The Eq.(8) is used to construct the concordance matrices. On the other hand, the Eq.(9) is used to construct Discordance matrices. In this step, after the matrices of concordance and discordance are established, matrices of concordance and discordance dominance are established. When these two matrices are generated, the threshold values in Eq.(10)-Eq (11) for both matrices are first calculated.

After two calculated threshold values are obtained, the concordance matrix equal value is compared to each concordance matrix element. In this comparison, if a concordance matrix element is greater than the computed threshold value, it takes on the value 1 , while if it is smaller, it takes on the value 0 . In this way, a concordance dominance matrix is formed.

On the other hand, after the discordance threshold value is calculated with the Eq (11), it is compared with each element of the discordance matrix. In this comparison, if the value of each element of the discordance matrix is greater than the discordance threshold, it takes 1 and if it is smaller, the value of 0 is taken. Total dominance matrix consisting of 0 and 1 is formed as a result of mutual multiplication of elements of concordance and discordance dominance matrices as indicated by Eq (12).

Table 3. The Aggregate Dominance Matrix $(E)$

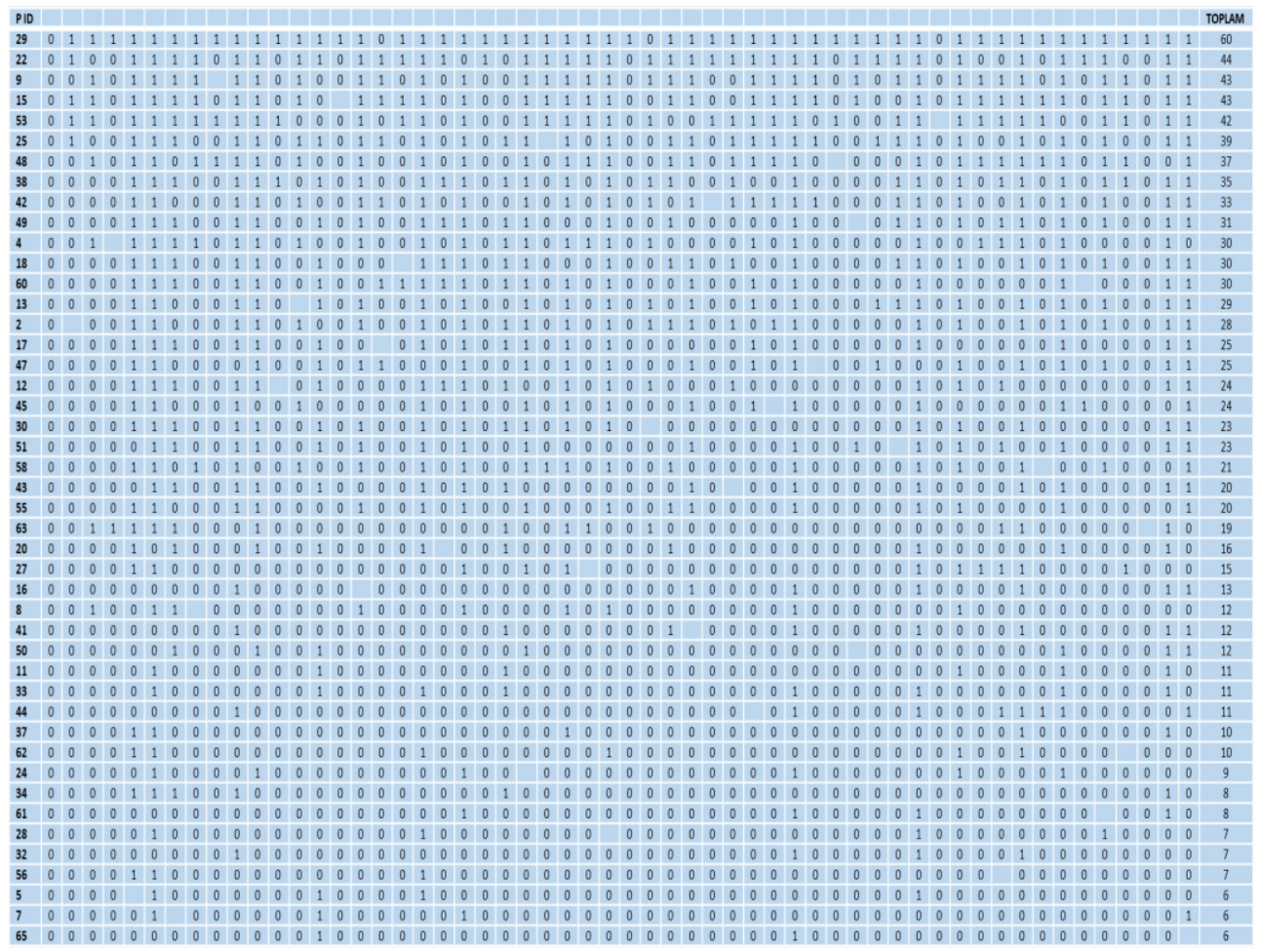

Table 3. shows the rows and columns of the aggregate dominance matrix generated. In the line of the matrix, the candidate with the highest sum of all criteria has become the most suitable candidate. The best candidate for the job is number 29 . 
Subsequently, candidates numbered 22, 9 and 15, respectively, are followed candidate number 29 in terms of their suitability for work. The candidate with the lowest suitability is 36.

\section{CONCLUSION}

As a result of this study, both methods applied were compared with each other and evaluations were made about which one would be the most correct result in terms of usage in the sector.

The Electre method compares the criterion values of the candidates and makes the conformity order. This method performs the evaluation by comparing whether the values are greater than or equal to the concordance threshold and whether the values is less than the discordance threshold. However, it does not take any action regarding how large the values are from each other, it also place candidates whose values are equal to each other in the same concordance set as the larger ones.

The Topsis method decides by looking at the Euclidean distance approach how far candidates are away from ideal. Even those values which are slightly different in magnitude among each other can be reflected in the order. Thus, the Topsis method gives the opportunity to analyze how close the candidates are to the ideal. For this reason, there are differences in the order of suitability of the candidates between the outputs of the two methods. When the results obtained in both methods are compared, the most suitable candidate is number 29 for business. However, since the methods calculate differently from each other, there is no similarity in the intermediate values.

Moving from here, it seems more appropriate to use the Topsis method in the problem of personnel selection. It is thought that the topsis method gives more reliable and precise results than Electre method and it is more accurate to use the Topsis method in the problem of personnel selection.

\section{REFERENCES}

1. Balezentis, A,. Balezentis, T \& Brauers, W, K., (2012). Personnel selection based on computing with words and fuzzy MULTIMOORA, Expert Syst. Appl. 39, pp:7961-7967.

2. Dursun, M., \& Karsak, E. E. (2009). A fuzzy MCDM approach for personnel selection.Expert Systems with Applications. doi:10.1016/j.eswa.2009.11.067

3. Güngör, Z., Serhadlioglu, G., \& Kesen, S. E. (2009). A fuzzy AHP approach to personnel selection problem. Applied Soft Computing, 9, 641-646.

4. Ishizaka, A., Nemery, P.(2013). Multi-Criteria Decision Analysis Methods and Software, John Willey\&Sons,Ltd. United Kingdom

5. Kabak, M., Burmaoglu, S \& Kazancoglu, Y., (2012). A fuzzy hybrid MCDM approach for professional selection, Expert Syst. Appl. 39, pp: 3516-3525.

6. Kelemenis, A., \& Askounis, D. (2010). A new TOPSIS-based multi-criteria approach to personnel selection. Expert Systems with Applications. doi:10.1016/j.eswa.2009.12.013

7. Sang, X., Lui, X \& Qin., (2015). An analytical solution to fuzzy TOPSIS and its application in personnel selection for knowledge-intensive enterprise. Applied Soft Computing 30, pp:190-204. 
8. Sarı, U. Irem, Öztayşi, B., Kahraman, C. (2013). Fuzzy Analytic Hierarch Process Using Type-2 Fuzzy Set: An Application to Warehouse Location Selection. Multicriteria Decision Aid and Artificial Intelligence Links, Theory and Applications. John Willey\&Sons,Ltd. United Kingdom

9. Triantaphyllou, E. (2000) Multi-Criteia Decision Making Methods: A Comparative Study, Kluwer Academic Publishers, Boston, USA

10. Zavadskas, E. K., Turskis, Z., Tamosaitiene, J, Marina, V (2008). Multicriteria Selection of Project Managers by Applying Grey Criteria. Ukio Technologinis ir Ekonominis Vystmas 14. (4): 462-477.

11. Zhang, X., \& Liu, P. D. (2010). Method for aggregating triangular fuzzy intuitionistic fuzzy information and its application to decision making. Technological and Economic Development of Economy, 16(2), 280-290. 